\title{
¿LEFEBVRE O KONSTANTINOV? RESPUESTA A UNA “CONTRARRÉPLICA"
}

\author{
LEFEBVRE OR KONSTANTINOV? \\ REPLYTO A “COUNTERREPLICATION"
}

\section{George I. García Quesada*}

\section{La crítica marxista sectaria y dogmática frecuentemente inicia aislando los textos de sus contextos, y después de otras obras del autor, para establecer una 'fórmula' u otra [...] Los marxistas sectarios no tienen mucho que decir, y todo lo que tienen que decir lo dicen de nuevo una y otra vez. Henri Lefebvre, Crítica de la vida cotidiana.}

\section{RESUMEN}

Este artículo responde a nuevas críticas formuladas en el artículo de Roy Alfaro Vargas titulado "Henri Lefebvre. Contrarréplica a George I. García" a mi libro Las sombras de la modernidad. Argumento contra la validez de dichas críticas a partir del cuestionamiento de sus formas de argumentación, así como de las principales nociones utilizadas por ese autor (historicismo, posmodernidad, dialéctica) y sus posiciones políticas.

PALABRAS CLAVE: VIDA COTIDIANA * MARXISMO * POSMODERNIDAD * CRÍTICA * HISTORICISMO

\section{ABSTRACT}

This article replies to new critiques formulated in Roy Alfaro Vargas's article "Henri Lefebvre. Contrarréplica a George I. García" to my book Las sombras de la modernidad. I dispute the validity of such critiques by questioning the formal aspects of his argumentation, as well as the main notions used by the author (historicism, postmodernity, dialectics) and his political positions.

KEYWORDS: EVERYDAY LIFE * MARXISM * POSTMODERNITY * CRITIQUE * HISTORICISM

Escuela de Filosofía, Escuela de Estudios Generales e Instituto de Investigaciones Filosóficas (INIF) de la Universidad de Costa Rica (UCR).

tuyog@hotmail.com 
En un texto anterior (García, 2008), respondí a varias críticas contra mi libro Las sombras de la modernidad (LSM, en adelante), aparecidas en el artículo "La sociología crítica de Henri Lefebvre", de Roy Alfaro Vargas. Allí argumenté que sus principales señalamientos contra dicho libro — pretendida ausencia del concepto de ideología y de la categoría de negación, concesiones indebidas al "conservadurismo posmoderno"- provenían de una lectura negligente de dicho libro $y$ de una tergiversación de sus tesis centrales. En términos precisos, indiqué que los yerros de dicha crítica ponían en entredicho incluso, que Alfaro hubiera leído el libro.

En su posterior "contrarréplica", Alfaro Vargas (2009) insiste en criticar ese libro más aún, a "García" - sin haberlo analizado, pero distorsionándolo con nuevos elementos. No rechaza los argumentos de mi réplica — los cuales están en todo caso documentados con referencias concretas en el libro- contra su interpretación de $L S M$, pero en este proceso muestra además desde qué nociones - no conceptos - ha elaborado sus críticas y presenta un nuevo conjunto de falacias para fundamentarlas. Dicho texto de Alfaro no es, pues, una contrarréplica, sino una nueva crítica que no respondió a mi anterior réplica. En tanto, que dicha "contrarréplica" es en realidad una nueva crítica, replico ahora a ella.

A continuación, argumentaré sobre la falta de validez de la crítica de Alfaro Vargas a LSM en el artículo "Henri Lefebvre. Una contrarréplica a George I. García", en tres sentidos: primero, indicando varias de las (nuevas) distorsiones de la lectura y falacias (descontando las ad hominem) en las que ha incurrido dicho comentarista; segundo, argumentando que las nociones de historicismo, posmodernidad y dialéctica, desde los cuales pretende formular su crítica son imprecisas o de plano ajenas a la tradición crítica del marxismo (Lefebvre, Adorno, Schmidt, etc.) en la que Alfaro Vargas afirma enmarcarse.

En cuanto al tercer aspecto, me referiré a las observaciones políticas del aludido artículo de Alfaro, las cuales muestran afinidades con la ideología estalinista. A lo largo de este artículo indicaré además, varios mecanismos retóricos que dicho texto de Alfaro comparte con la escolástica soviética (cfr. Blakely, 1969) y en particular, con el diamat del socialismo histórico.

\section{¿QUÉ ES HISTORICISMO?}

En sintonía con el epígrafe de Mario Bunge que encabeza su "Contrarréplica", Alfaro Vargas hubiera podido titular dicho texto, al mejor modo popperiano, "Miseria del historicismo". Esto, debido al repetitivo reclamo que le hace a $L S M$ por su apego a la historicidad, pero además porque, al igual que Popper, Alfaro construye - de nuevo- un fantoche para luego criticarlo. Sin embargo, mientras que Popper explicita que el "historicismo" que critica es una construcción ideal, Alfaro pretende hacer pasar su interpretación arbitraria de $L S M$ como si se refiriera realmente a las tesis de mi libro.

Alfaro indica hacia el final de su "contrarréplica" que es necesaria la "articulación dialéctica entre lo histórico y lo lógico" (2009: 111). Si eso era lo central de su crítica, bien hubiera podido ahorrársela, pues la lógica de la interpretación de $L S M$ se basó en una periodización referida a los cambios en la lucha de clases en Europa a lo largo de varias coyunturas y de cómo la teorización de Lefebvre (en ella su dialéctica) sobre lo cotidiano fue respondiendo a ellas. Pero, si Alfaro no encontró referencias a un concepto (el de "ideología") que aparece explícitamente desarrollado unas 24 veces a lo largo del libro (cfr. García, 2008: 62) o al de "negatividad" (cfr. García, 2008: 61-62), no sorprende que no se haya tomado la molestia de pensar sobre el marco categorial subyacente en la periodización propuesta en ese libro. No se trata ya siquiera de un problema de interpretación, sino de simple lectura.

Un poco de atención a la estructura del texto -empezando por analizar el índice, por ejemplo- le hubiera permitido diferenciar tres niveles de análisis articulados en una totalidad: el nivel del desarrollo conceptual de las obras de Lefebvre, el de la historia intelectual en la que ellas se desarrollan y el de la historia social de las coyunturas en las que el teórico francés elaboró sus planteamientos sobre lo cotidiano (de hecho, esto es muy claro en la estructura 
de los tres capítulos principales del texto). Es una estructura que, dicho sea de paso, coincide con el modelo hermenéutico propuesto por Jameson (1989), quien a su vez se inspiró en la teoría de los tiempos diferenciales del historiador Fernand Braudel ${ }^{1}$.

La "contrarréplica" de Alfaro pretende hacer creer que en $L S M$ hay un divorcio entre lo categorial y lo histórico, además, que este se impone unilateralmente sobre lo teórico en mi interpretación de Lefebure. Esto es falso y rebuscado, como tantas otras afirmaciones de Alfaro a las que me referí detalladamente en mi anterior réplica. Por supuesto que no es cierto que "en el pensamiento dialéctico estuvieran separadas la historia y la teoría (lo lógico)" (Alfaro, 2009: 107), pero eso nunca fue sostenido en dicho libro.

La periodización de la obra de Lefebvre fue el criterio central de $L S M$, pero eso no implicó que se redujeran las teorías lefebvrianas a puro contexto social, como afirma Alfaro ${ }^{2}$. Por

1 Resulta totalmente gratuito, por tanto, relacionar la historización de $L S M$ con la sociocrítica (Alfaro, 2009: 104). La hermenéutica marxista, desarrollada más tempranamente alrededor de la crítica literaria, buscó siempre historizar el texto para comprender su lugar en el entramado social desde el que fue producido. Además del citado Jameson, para mencionar solo clásicos, véanse Lukács (1973), Bajtín (2005), Goldman (1985) y Williams (1997).

2 Por lo demás, algunas de las críticas de Alfaro Vargas a $L S M$ denotan su falta de familiaridad con la producción teórica de Lefebvre. Por ejemplo, indica que "García" tiene una "obsesión genetista" por buscar el tema de lo cotidiano en Marx y Engels, pero fue Lefebvre (1991: 148-175) quien primero retomó los elementos de crítica de la vida cotidiana en Marx, tema sobre el cual este servidor amplió en un ensayo como insumo para un curso que imparte regularmente. ¿Lefebvre tenía, pues, una "obsesión genetista"? También Marx habría sido "genetista" entonces, por haberle dedicado cientos de páginas en El capital, a los orígenes históricos del capital. También afirma Alfaro (2009: 104, nota 3) que "García" confunde cotidianidad y vida cotidiana al hablar sobre crítica de la vida cotidiana. No hay tal confusión. Esto ya estaba debidamente explicado a lo largo de LSM y muy claramente entre páginas 61 y 65 . Por una parte, criticar no significa "aniquilar" racionalmente un disvalor; significa evaluar y en particular, establecer límites y posibilidades. Por otra parte, ¿por el contrario, el texto explica y desarrolla las categorías en relación con las coyunturas en las que surgieron (criterio básico de la totalidad dialéctica). En ningún momento se abandonó la reflexión conceptual en el libro; lo que sí se hizo fue historizarlas. El mismo Lefebvre (1976b: 8-9) indicó que sus teorías habían ido cambiando con las coyunturas históricas: al respecto indiqué el caso de sus concepciones de dialéctica (García, 2008: 61), ejemplo al cual Alfaro Vargas ha hecho caso omiso, como respecto a casi todos los argumentos de mi réplica, en su "contrarréplica" ${ }^{3}$.

A raíz de esa falsa interpretación, Alfaro Vargas desarrolla a lo largo de ese escrito una línea de argumentación que, más que anti-historicista, es anti-histórica. En palabras de Alfaro:

La tesis que nos guiará es la siguiente: en el análisis del pensamiento lefebvriano, García (2001) enfatiza lo histórico, con lo cual la posición cae dentro de un historicismo, el cual reduce la propuesta de Lefebvre a un activismo político, sometido a la diferencia posmoderna (2009: 104). [Así, afirma que] García pretende, con un sesgo positivista, inculcar dentro de lo lógico, lo histórico (2009: 107).

La "articulación dialéctica entre lo histórico y lo lógico" es dejada de lado por dicho comentarista en favor de una perspectiva en

qué Lefebvre tituló Crítica de la vida cotidiana a la trilogía que sirvió como corpus principal a $L S M$ ? ¿Lefebvre estuvo confundido por 45 años sobre este concepto? Otro ejemplo: califica a "García" de apocalíptico, por indicar que para Lefebvre la revolución es la única alternativa a la catástrofe. Pero resulta que quien dice que con la mundialización se plantea la opción entre metamorfosis social y destrucción planetaria no es "García", sino... ¡Lefebvre! (1976a: 6). ¿Era Lefebvre, por tanto, "apocalíptico"?

3 De allí también la "omisión" que encuentra Alfaro del método regresivo-progresivo en $L S M$. A lo largo del libro se muestra cómo la producción de Lefebvre (en cuenta su dialéctica) se desarrolló a partir de ciertas bases teóricas hacia formas más concretas, que superaban sus anteriores formulaciones en interacción con los respectivos cambios socio-históricos. Véase al respecto, Lefebvre (1997: 65-67). 
la que, frente a lo que él considera relativismo posmoderno, prima lo lógico desligado de lo histórico. Quedamos notificados, pues que lo lógico según Alfaro, no es histórico; a esta concepción metafísica me referiré en el apartado sobre dialéctica más adelante. Por lo demás, las alusiones de Alfaro a un presunto positivismo en $L S M$ carecen de fundamento alguno; solamente indicaré que el reseñador parece no haberse percatado de que hace ya alrededor de cuarenta años en Costa Rica la teoría de la historiografía postula -en sintonía con el marxismo y con la Escuela de los Annalesque no se puede hacer historiografía sin un aparato categorial; desde este enfoque, la pretensión positivista de limitarse a la descripción es inaceptable; la historia es ciencia social (cfr. Díaz, Boza e Ibarra (comps.), 2007) ${ }^{4}$.

Por esto es sorprendente que Alfaro se deje decir que periodizar es positivista (2009: 107, nota 16), pasando por alto que esa es la operación historizadora por excelencia y que obviamente, implica una teoría sobre la cual se fundamente tal periodización (cfr. Jameson, 2004: 37-44). De su desafortunado comentario al respecto, se seguiría que un estudio marxista no debería periodizar para no caer en el positivismo, lo cual es a todas luces un sinsentido. Lo más llamativo de la posición de Alfaro es su descalificación sin más a la historización. Si Alfaro quería cuestionar la historización planteada en el libro, por una supuesta falta de aparato categorial, hubiera podido plantear una discusión en ese sentido. Pero no cuestiona la periodización específica del libro, sino... jel hecho de que haya periodización! Este reclamo sería congruente con una posición que busca esencias no históricas - como lo hacen el sentido común o algunas filosofías prekantianas

4 Esta equiparación de Alfaro de historia con positivismo es alarmante: por ejemplo, ¿̇erá que los estudios de Hobsbawm (por ejemplo, 1998) sobre el capitalismo o de Thompson (1989) sobre la formación de la clase obrera inglesa no son obras de historia? Parece que según la noción que sigue Alfaro ningún historiador podría ser marxista, pues por definición sería positivista. Estas observaciones de Alfaro cuestionan lo que él considera bajo los términos "historia" y "positivismo". como el diamat estalinista-, pero que no tiene mayor cosa que ver con dialéctica.

Historizar la teoría es el primer paso para pensar socio-históricamente el propio contexto; de lo contrario, afloran los esquematismos al modo soviético, que pretendía universalizar ciertas fórmulas abstractas para toda formación económico-social. Es necesario ser consciente del contexto social en el que se formulan los conceptos y teorías para poder valorar su aplicabilidad a sociedades distintas a aquellas en las que surgieron; Lefebvre siempre resaltó esta necesidad a lo largo de sus textos y resulta irónico que alguien, afirmando seguirlo, prefiera deshistorizar sus aportes. Ya decía Korsch (1977: 37-46) hace casi cien años (¿sería un "posmoderno" avant la lettre?), que se debe aplicar también el método marxista al propio marxismo. Nunca se sostuvo en $L S M$ que "en el pensamiento dialéctico estuviesen separadas la historia y la teoría (lo lógico)" (Alfaro, 2009: 107): por el contrario, la historización de la teoría en $L S M$ surge desde la misma teoría marxista de la historia.

Por otra parte, uno de los yerros más gruesos de la "contrarréplica" es precisamente la de asimilar el historicismo dentro del posmodernismo. El absurdo es evidente: resultaría que por ser historicista, ya el romanticismo sería posmoderno. En realidad, el historicismo surge con la conciencia histórica moderna, entre mediados de los siglos XVIII y XIX, y forma parte de un régimen temporal que abrió la posibilidad de ciencias como la geología o la biología evolutiva ${ }^{5}$.

Es desde esta condición histórica que Marx (1993: 92) desarrolla su teoría de la historia, en la cual las conceptualizaciones ${ }^{6}$ e incluso, los sentidos humanos son producidos históricamente: es desde allí que él y Engels

5 Sobre los cambios culturales de esta época, cfr. Williams, 1983 y 2003.

6 Por ejemplo, su explicación sobre por qué Aristóteles no podía llegar a una teoría del valor (cfr. Marx, 2009, vol. 1: 72-74). En El capital este recurso hermenéutico es muy recurrente, sobre todo cuando Marx se refiere a por qué economistas que él respetaba no desarrollaron todas las implicaciones de sus respectivas teorías. 
afirman al inicio de La ideología alemana con cierta exageración, pero contundentemente- que "no conocemos más ciencia que la ciencia de la historia" . De hecho, fue Marx y no "García", quien afirmaba que:

... incluso las categorías más abstractas, a pesar de su validez — precisamente debido a su abstracción- para todas las épocas, son ellas mismas sin embargo, en el carácter específico de su abstracción, también un producto de relaciones históricas, $y$ poseen toda su validez sólo para y dentro de estas relaciones (1993: 105).

Pero Alfaro considera al "historicismo" además, como una variante del posmodernismo y esto lo sostiene relacionando a Foucault con el historicismo. Su argumentación en este aspecto muestra la lógica desde la cual este emprende su crítica. La falacia consiste en partir de que Foucault es posmoderno - una afirmación sumamente problemática ${ }^{8}$ - . Pero, además, supone que Foucault es historicista $y$ que García es historicista. Ergo, García es posmoderno. Y si Foucault es historicista y posmodernista, el historicismo es posmoderno.

Esta misma "lógica" — que evidentemente no es ni formal ni dialéctica- es la misma que sigue para llegar a una conclusión falaciosa que luego le atribuye a $L S M$ : cuando Alfaro (2009: 104) afirma que allí, como lo político $y$ lo cotidiano son ambos relacionales, ambos son la misma cosa. La falacia de Alfaro consiste en definir un objeto a partir de una cualidad suya. Según esa "gnoseo-lógica", si Pedro es costarricense y Juan es costarricense, entonces Pedro y Juan son lo mismo. La "circularidad" y

$7 \quad$ En mi "Réplica" (2008: 62) indiqué cómo según la lógica de Alfaro, incluso Marx sería "posmoderno"; en su "Contrarréplica" ratifica tal conclusión. Pero ahora, además de Marx habría que considerar "posmodernos" a Gramsci, Lukács, Bloch, Lefebvre y Jameson... en fin, prácticamente a todos los marxistas críticos.

8 Véase, por ejemplo, la complejización planteada por Carlos Aguirre (2010) respecto a la historiografía foucaultiana; véanse también, Rojas Osorio (2003) y Grüner (1995). petitio principii que "encuentra" Alfaro a inicios de $L S M$ (y sobre la que luego insiste), en cuanto a la definición de lo cotidiano y su relación con la política, solamente se encuentra en la falacia que construyó el mismo Alfaro ${ }^{9}$.

Pero, ¿habrá necesidad de recordarle al lector cuál es la versión del marxismo más fervorosamente anti-historicista? Además de la versión althusseriana - que tenía muy claro su rechazo a la dialéctica- se trata del diamat soviético, el cual Alfaro (2009: 105) califica acertadamente como la ideología oficial del Estado ruso, aunque no parece reconocerle su propia deuda gnoseo-lógica. Desde las nociones de Alfaro Vargas, ciertamente Konstantinov - célebre autor de varios manuales de diamat - no tendría que preocuparse por la etiqueta de "posmoderno", pues partía de dogmas incuestionables sin tener que preocuparse por la investigación empírica.

\section{¿QUÉ ES POSMODERNIDAD?}

El historicismo surge de un régimen temporal típicamente moderno y si el posmodernismo tiene una particular bête noire esa es, precisamente, la historia. Que esto le parezca a Alfaro Vargas escandalosamente relativista, solo indica la confusión que este tiene respecto a la relación modernidad-posmodernidad, una confusión que comparte, eso sí, con muchos de los defensores de la posmodernidad en la academia criolla $^{10}$.

$\overline{9} \quad$ Otra falacia evidente aparece cuando Alfaro le atribuye a $L S M$ negar que en Lefebvre haya utopía. Dice el comentarista que hay una contradicción entre el concepto de utopía que critica (2009: 106) en páginas 33 y 41 de $L S M$ : en la primera, se afirma que Lefebvre "se negó a hablar de la utopía más que en términos de negación del orden social moderno" y en la otra, que el horizonte utópico de la crítica lefebvriana estaba en la disolución de la vida cotidiana (esto es, en su negación). Alfaro infiere que una utopía negativa no es una utopía (2009: 103). Por otra parte, el "double bind psicológico" que diagnostica en cuanto al concepto de utopía de "García", lo podría haber encontrado ya en Marx y Engels. Cfr., por ejemplo, Engels, 1976.

10 Esta equivocación se basa, en parte, en considerar que el posestructuralismo es, per se, posmoderno. Sobre esta confusión, cfr. García, 2006. 
La noción de posmodernidad en los textos de Alfaro Vargas es tan imprecisa como recurrente. Pero, aunque el punto de partida de las dialécticas de Hegel y de Marx es el cuestionamiento de lo que pasa por obvio, Alfaro prefiere quedarse con sus prejuicios sobre lo que considera posmodernidad. Así, en el resumen en inglés de su Contrarréplica, Alfaro (2009: 103) afirma que allí muestra el nexo entre "el pensamiento de García y la ideología posmoderna". Sin embargo, no dice ni una sola palabra sobre las críticas en el capítulo 4 de LSM a aspectos medulares del posmodernismo. Extrañamente, Alfaro tampoco plantea en sus artículos un concepto de posmodernidad ${ }^{11}$; solo menciona en sus bibliografías el famoso ensayo de Jameson: Postmodernism, or the cultural logic of late capitalism.

Las valoraciones de Alfaro, sin embargo, carecen de asidero alguno en la teoría del marxista estadounidense, quien no desvalora a la posmodernidad por ser producto del capitalismo. Para Jameson, por ejemplo, un marxismo posmoderno no es un oxímoron, pues posmodernidad no es una corriente de pensamiento o una ideología, sino una lógica de la que pueden surgir formas culturales muy diversas. De haber leído a Jameson, con su exhortación a historizar siempre ${ }^{12}$, Alfaro Vargas posiblemente lo habría definido como historicista y por tanto - según su noción- como posmoderno; etiqueta, esta última, que - al modo del diamat (cfr. Blakely, 1969: 99-107) — funciona como condena moral, aunque no como concepto.

Pero Jameson lo dice inmejorablemente:

11 Debido a varios compromisos académicos insoslayables, he retardado esta respuesta a la Contrarréplica de Alfaro, quien entre tanto ha publicado algunos artículos posteriores en los que indica qué entiende por posmodernidad, indicando allí algunas características, pero no un concepto de posmodernidad propiamente. Valga decir que en ellos se muestra la misma inconsistencia de fondo respecto al concepto de posmodernidad que encontramos ya en los textos a los cuales aquí respondemos. Cfr. Alfaro y Cruz, 2009.

12 Jameson, de hecho, ha caracterizado explícitamente su producción teórica como historicista. Cfr. Buchanan (ed.), 2007: 24.
... la mayoría de las posiciones políticas (...) son en realidad posturas moralizantes que procuran elaborar juicios definitivos sobre el fenómeno del posmodernismo, ya se lo estigmatice como corrupto o bien se lo salude como una forma de innovación cultural y estéticamente saludable y positiva. Pero un análisis auténticamente histórico $y$ dialéctico de dichos fenómenos (...) no puede darse el empobrecido lujo de tales juicios moralizantes absolutos: la dialéctica está 'más allá del bien y del mal' en el sentido de que es fácil tomar partido, $y$ de allí el glacial e inhumano espíritu de su visión histórica (...) El asunto es que estamos dentro de la cultura del posmodernismo a tal extremo que su repudio facilista es tan imposible como complaciente y corrupta es cualquier celebración igualmente facilista de ella (...) En lugar de la tentación de denunciar las complacencias del posmodernismo como un síntoma final de decadencia o saludar las nuevas formas como heraldos de una nueva utopía tecnológica y tecnocrática, parece más apropiado evaluar la nueva producción cultural dentro de la hipótesis de trabajo de una modificación general de la cultura misma, con la reestructuración social del capitalismo tardío como sistema (1997: 49).

Dicho de otro modo: Alfaro pretende legitimar - aparentemente sin percatarse, pues va contra sus propias tesis- su noción de posmodernidad en una teoría que por una parte, es historicista $y$ que por otra, no permite una reducción de dicha lógica cultural a un asunto moral, como lo hace tal comentarista costarricense, aunque el título del más famoso ensayo de Jameson le pudiera indicar otra cosa a un lector prejuiciado y poco atento. Deja la impresión de que "posmodernismo" es para Alfaro más bien algo, así como, una caja de sastre en la que deposita todo aquello que no le gusta, de modo que tal palabra funciona estrictamente como imprecación. 
Además es llamativo que Alfaro no cite a ningún otro autor marxista que haya teorizado sobre la posmodernidad. ¿David Harvey? ¿Terry Eagleton? ¿Peter Dews? ¿Eduardo Grüner? ¿Alex Callinicos? En los textos de Alfaro Vargas, tales importantes autores contemporáneos, sus aportes $y$ tesis no existen; no aparecen siquiera en sus bibliografías, como al menos lo está el mencionado libro de Jameson. Desde el "método dialéctico" de Alfaro no es necesario dialogar siquiera con los autores de la propia tradición marxista que él invoca para legitimarse como crítico. Pareciera bastarle con unos cuantos libros sobre dialéctica para interpretar el mundo entero y sus especificidades. Esto resulta muy claro cuando habla, precisamente, sobre dialéctica.

\section{¿QUÉ ES DIALÉCTICA?}

Entre las afirmaciones de la "contrarréplica" de Alfaro, se encuentra la mención de "la confusa comprensión de la dialéctica negativa que tiene García” (2009: 106), pero no habla de las observaciones e interpretaciones sobre la dialéctica de Lefebvre en páginas como la 39 (en relación con la praxis), 41 y 48 (sobre la totalidad dialéctica de realidad y apariencia), 53, 59, 60 y 71 (tensión negatividad-totalidad), 77, 94 y 98 de $L S M$, por hablar solo de los dos primeros capítulos. Se entiende que Alfaro no se refiriera a la dialéctica en $L S M$ - ya hemos observado que su método no analiza los textos-, pero al menos debió haberse referido a lo que el texto dice explícitamente sobre el tema. Esta lectura negligente ya la había aplicado a la categoría de negatividad y al concepto de ideología (cfr. García, 2008: 61-62); ahora ratifica que tal negligencia forma parte de su método crítico.

Sobre la dialéctica, nos dice Alfaro que es una "herramienta", concepción que además de manifestar un sesgo de racionalidad instrumental, deriva de una concepción mucho más cercana al neokantismo que a la dialéctica de herencia hegeliana (véase por ejemplo, Rose, 2009: 1-50). En $L S M$ se indicaban divergencias en cuanto a la concepción de dialéctica entre Lukács, Lefebvre y Adorno (LSM, 71 y 104), e incluso en diferentes momentos de la producción de Lefebvre; esto es, el libro planteaba la existencia de diferentes dialécticas, tema que reiteré en mi réplica (2008: 104). Sobre esto tampoco comenta nada Alfaro Vargas, quien supone que hay solo una dialéctica negativa, la cual es desconocida por "García".

Mientras que la Dialéctica negativa o la Teoría estética de Adorno plantean un modelo de dialéctica de dos términos que no resuelve nunca sus tensiones, el que Lefebvre desarrolla magistralmente en La producción del espacio plantea un modelo triádico - también de carácter negativo - muy distinto al adorniano. Más recientemente, Jameson ha argumentado que más que hablar de una dialéctica (sea como sistema o como método), lo más apropiado es hablar de lo dialéctico para evitar la cosificación del método descosificador por excelencia (cfr. 2009: 3-70). Por su parte, Žižek (1998: 235-253; 2001: 88-97) ha ilustrado la multiplicidad de modelos de dialéctica en el mismo Hegel.

Desde Kant, fijar fórmulas es propio del entendimiento, mientras que la dialéctica procede de la razón. La dialéctica no es formalizable, no se puede cosificar; por lo demás, Lefebvre (1979: 275) es claro en ello en su texto de $1946^{13}$ : las de la dialéctica "son leyes universales y concretas. Pero no nos permiten prever ni deducir un objeto cualquiera. No reemplazan a la investigación ni al contacto con el contenido". O sea, la dialéctica sería lógica concreta y como tal, no desliga forma y contenido como unidad históricamente determinada; parte de la superación de esa oposición (1979: 201-207). Por el contrario, las críticas de Alfaro contra el "historicismo" de $L S M$ han dejado en claro que para dicho comentarista lo lógico más bien se parece a lo que Marx y Engels llamaban "metafísica", esto es, un discurso formalizado y deshistoriza$\mathrm{do}^{14}$, y que su concepción de dialéctica es más deudataria del diamat (cfr. Konstantinov et ál., 1985: 125-162) que de Hegel o Marx.

13 Valga insistir en que la dialéctica de Lógica formal, lógica dialéctica no es la misma que Lefebvre elabora a partir de los 60 , como ya se había indicado (García, 2008: 61).

14

El propio Engels (1962: 79) relativizaba "las leyes del pensamiento humano, es decir, la lógica y la dialéctica". 
También le endilga a "García" el autor de la mencionada "Contrarréplica", la dudosa cualidad de pasar por alto la categoría de totalidad, por no compartir su visión de la sociología, visión que sostiene precisamente el parcelamiento disciplinar el cual, según "La sociología crítica...", al filósofo le corresponde dedicarse a cuestiones de método. Esta acusación ya no solo se basa en una lectura negligente de $L S M$ (en el cual, el tema es abordado reiteradamente, como hemos indicado unos párrafos atrás), sino incluso de mi corta réplica. Atrapado en su monólogo, Alfaro no parece haber leído allí las citas de Harvey y de Grüner - por no hablar de mis propias argumentaciones - sobre la categoría de totalidad $y$ sus implicaciones contra el parcelamiento disciplinar defendido por Alfaro Vargas.

Por ello, insisto sobre este aspecto, ahora a través de Eric Hobsbawm contra esa división del conocimiento:

... el extinto J. Schumpeter, uno de los críticos más inteligentes de Marx, intentó distinguir al Marx sociólogo del Marx economista, y uno podría hacerlo fácilmente con el Marx historiador. Pero estas divisiones mecánicas son engañosas, $y$ por completo opuestas al método de Marx [...]. El examen de diversos modos precapitalistas de producción es, en este ensayo [Formas que preceden a la producción capitalista, de Marx], un brillante ejemplo de ello $y$, de paso, ilustra lo totalmente erróneo que resulta concebir al materialismo histórico como interpretación económica (o sociológica) de la historia (1974: 11).

Dicho de otro modo: el enfoque marxista no se reduce a una sociología ${ }^{15}$, aunque obvia-

15 En concreto, Lefebvre critica "que hayan ideólogos -notablemente en Alemania (Weber, Mannheim, etc.) - que han reducido las ciencias históricas y sociales, junto con la filosofía y la teoría del conocimiento, a la sociología" (Lefebvre, 1991: 252). Que Alfaro se empeñe en asegurar que el enfoque de Lefebvre es sociológico (2009: 108) solo indica que Alfaro tiene una concepción de la sociología que no es la de Lefebvre - ni la de Marx-. mente esta tiene cabida y es necesaria en el marxismo; este fue el concepto que planteó Lefebvre en sus luchas teóricas contra el dogmatismo pseudomarxista y que reivindiqué, tanto en $L S M$ como desde mi anterior réplica contra las concepciones parceladas del conocimiento disciplinar. La explicación de ese planteamiento teórico la remití a páginas específicas de $L S M$ en la nota 1 de mi réplica, pero Alfaro optó por no darse por enterado. Ello le hubiera implicado responder a argumentos concretos sobre el tema y le hubiera dificultado entrar en divagaciones inatinentes $y$ descalificaciones antojadizas.

La concepción de dialéctica de Alfaro queda retratada cuando afirma (2009: 110) que para ir más allá de Lefebvre habría que dejar de lado la producción social del espacio. Se trata, pues, del proyecto de una dialéctica de la naturaleza; una aplicación sobre la cual Marx no produjo teoría y a la que Lefebvre tampoco le prestó mayor atención. En ambos autores -al igual que otros como Adorno o Lukács-, el énfasis recayó sobre la praxis como constitutiva de mundo y particularmente, sobre el tema de la alienación ${ }^{16}$.

El propio autor sobre el cual se basa Alfaro Vargas para justificar su eventual recurso a la física para investigar el tema del espacio, Bitsakis, fundamenta el grueso de su interpretación sobre las consideraciones de Engels y Lenin, calificando a Marcuse como un "antimarxista muy particular" (Bitsakis, 1975: 53), y notando que Lefebvre rechazaba la dialéctica de la naturaleza como una forma de filosofía deformada e institucionalizada (1975: 235). Las filiaciones filosóficas de Bitsakis no concuerdan, pues, con las de los autores que Alfaro suele invocar como sus referentes - Marx, Lefebvre, Adorno, Schmidt, etc.

$16 \quad$ Alfred Schmidt ha argumentado que desde la producción de Marx no se pueden justificar los abordajes desde la filosofía de la naturaleza. Indica: "¿es posible (...) una dialéctica materialista de la naturaleza en sí? ¿Materialismo y dialéctica no se vuelven recíprocamente incompatibles como se observó a menudo, si por naturaleza se entiende lo que las ciencias exactas establecen acerca de ella? (...) a la primera pregunta se debe responder negativamente y a la segunda afirmativamente" (Schmidt, 1976: 197). 
Pero Alfaro afirma que esa dialéctica de la naturaleza es necesaria para entender lo social: desde su concepción, las mediaciones entre lo social y lo natural prácticamente no existen. Afirma que el par de lo mecánico y lo relativo:

... nos permitirá aprehender los procesos físicos en lo social y viceversa, con el fin de entender cómo el tiempo absoluto de la física mecánica ha determinado ideológicamente el aparato cognitivo y lo social, así como las categorías de tiempoespacio desde Kant (2009: 110).

La dialéctica de espacio-tiempo y sociedad, empero, ha sido abordada ya reiteradamente desde hace muchas décadas sin necesidad de apelar a modelos importados de los estudios naturales, por lo cual tal formulación, además de evidentemente reductiva, ha sido rebasada.

Al hablar sobre los temas de espacio y tiempo, Alfaro Vargas menciona dos artículos recientes (de Castree y de Sewell), pero no presta ninguna atención a autores fundamentales que destacaron por desarrollar esas categorías en el marxismo, como Bloch, Benjamin, Althusser, Harvey o Jameson, tan ausentes como los latinoamericanos Bolívar Echeverría, Eduardo Grüner o Sergio Tischler; ni qué decir de interlocutores no marxistas indispensables para esos temas, como Heidegger o Bourdieu. Diciéndose marxista, Alfaro no parece creer necesario manejar textos básicos de la tradición marxista sobre los temas que él escribe.

Pero, aunque sus artículos sugieren un conocimiento fragmentario del marxismo $y$ su historia, la afinidad de Alfaro Vargas con la dialéctica de la naturaleza lo acerca sin duda a cierta tradición de lectura del marxismo: un marxismo sin categorías de praxis $^{17}$

$17 \quad$ Alfaro solo esgrime la praxis como criterio para criticar a Derrida (2009: 109). Dicha crítica se encuentra en todo el desarrollo de $L S M-y$ especialmente en los capítulos 3 y 4, donde se critica al estructuralismo y al posestructuralismo-, pues todo el proyecto de crítica marxista de la vida cotidiana es una elaboración de la teoría de la praxis. Alfaro también prefirió pasar esto por alto con tal de calificar a "García" de derrideano. o alienación, ni historia. Alfaro Vargas leyó a Lefebvre y entendió a Konstantinov.

\section{¿Y LA POLÍTICA?}

Los desaciertos puntuales en la "contrarréplica" de Alfaro son tantos que no me podría detener en cada uno de ellos. Señalaré, sin embargo, uno del cual se derivan serias consecuencias políticas. Su obsecación contra todo aquello que no calce en lo que él considera "dialéctica" y "marxismo" lo llevan a despreciar como "posmoderna" la categoría de diferencia. Con ello, de nuevo sugeriría que Lefebvre -quien entre otras cosas tituló un libro suyo de 1970, Manifiesto diferencialista - es posmoderno ${ }^{18}$, aunque su descalificación se basa principalmente en que "García" habría introducido "irreflexiva" e "ingenuamente" un elemento derrideano en la dialéctica. Admite que Lefebvre desarrolla la diferencia en su dialéctica, pero le inventa a "García" una concepción de diferencia que tiene rasgos derrideanos y que nunca aparece en $L S M$ : de nuevo, un extenso y mal fundamentado rodeo para afirmar que "García" es posmoderno.

También se remite a Derrida para descalificar a los movimientos sociales "que buscan afirmar su pretendida diferencia" (2009: 109) y menciona explícitamente a feministas, movimiento gay y ecologistas. De ese modo aflora el sectarismo poco disimulado de Alfaro; como en la política de los obsoletos partidos comunistas de corte soviético, concibe a los movimientos sociales como los pordioseros de la lucha de clases (sobre este sectarismo politicista, cfr. Gallardo, 2006: 125-129) y sugiere que buscan reivindicaciones "posmodernas"; esto es, las descalifica. Estas consideraciones resultan sorprendentes, en tanto que Alfaro pretende basar sus posiciones en las teorías de Lefebvre, un

18 Cfr. Lefebvre, 1975 y 1981: 109-122. Recordemos que el capítulo final de La producción del espacio se titula "De las contradicciones del espacio al espacio diferencial". La misma oposición en Marx entre la forma natural $y$ la forma valor contiene ya la crítica a la homogeneización (por la mercancía) sobre lo singular y la diferencia, un tema desarrollado consecuentemente por la crítica de Adorno a la identidad. Cfr. Adorno, 2005. 
autor que constantemente buscó repensar los conflictos sociales de acuerdo a las necesidades cotidianas de los sectores sociales subalternos (cfr. LSM, p. 209). La de Alfaro es, por el contrario, una posición política - como su estilo de argumentación - de raigambre estalinista que ha tenido consecuencias lamentables a nivel humano y ambiental.

Además de Lefebvre, autores como Helio Gallardo, por el contrario, se han referido a la necesidad de consolidar un sujeto histórico amplio $y$ a partir del carácter diferencial de los sectores que lo conforman. Frente a un modelo burgués basado en un consenso ideal, la articulación de los sectores populares se basa en el disenso, en el reconocimiento de sus diferencias (cfr. Gallardo, 2000: 19-47; 2006: 114-129).

Por ello, aún sin tomar en cuenta el claro salto lógico que hace Alfaro Vargas, no extraña que desde esas coordenadas políticas, tal comentarista insinúe que quien escribe estas páginas se dedica a "crear mercancías académicas 'novedosas' para impulsar el mercado capitalista" (Alfaro, 2009: 111) ${ }^{19}$. Su extravío es tal que me acusa - no al texto- de mezclar pensamiento crítico con deconstrucción, una afinidad que nunca he tenido - la reconocería si ese hubiera sido el caso-, y mucho menos cuando escribí $L S M$. Pero la acusación es indicativa del dogmatismo de Alfaro; es un purista, a diferencia de todos aquellos autores que hicieron aportes significativos a la teoría marxista, Henri Lefebvre claramente entre ellos. Pensar consecuentemente desde un planteamiento dialéctico no implica desechar a priori todo lo que se haga fuera de él, sino ser capaz de dialogar con otras corrientes teóricas y fenómenos sociales, distinguir e incorporar lo que allí aparezca como valioso. Pero para Alfaro Vargas, la sola alusión de cercanía a autores como Foucault, Žižek o Derrida funciona como descalificación, un mecanismo que, irónicamente, le fue aplicado a Lefebvre muchas veces desde la "ortodoxia" estalinista.

19 Como se indicó anteriormente, el enfoque de LSM solo le parecería "novedoso" a alguien que desconozca la tradición del marxismo crítico inaugurada en los años 20 del siglo pasado.

\section{EPÍLOGO}

En general, el método crítico de Alfaro consiste en elaborar un interlocutor ("García", en este caso) que, entre otras características, no sabe cuáles son sus influencias teóricas, que hace "confesiones ingenuas", que tiene una "maraña de incomprensiones", que vende "mercancías académicas", etc. Esta retórica se dirige a crear una figura de autoridad (él mismo) (cfr. Blakely, 1969: 121-122), desde la cual se permite monologar, lanzando ocasionales comentarios condescendientes sobre sus interlocutores. La comprensión y análisis del texto son prescindibles; en su método se trata de que la autoridad diga lo que ya pensaba sin reparar en los argumentos ajenos $y$ desde una lectura superficial, de buscar fragmentos que legitimen la interpretación que ya se había formado previamente sobre el texto.

Luego, ese método crítico sigue los principios de la caricatura: toma una frase o concepto aislados y los exagera hasta la deformación, etiqueta esos elementos aislados (cuanto más descalificante la etiqueta, mejor para tal método), dejando finalmente, la impresión de que en el texto criticado hay influencias, imprecisiones $y$ contradicciones que no calzan con lo que él supone que sería el marxismo verdadero o incluso con la lógica elemental. Es desde este proceder que le reclama a $L S M$ ser, a la vez, genetista e historicista, leninista y posmodernista, filosófico y activista, mesiánico y apocalíptico: las incongruencias que critica en el texto provienen en realidad de la incongruencia de su método.

Esta descalificación mediante la adjudicación de etiquetas - ¿debería sorprendernos?es un clásico recurso de la escolástica soviética. Si para el estalinismo llamar a alguien "revisionista" o "idealista" (o "ultraizquierdista" o "voluntarista", etc.) cancelaba cualquier discusión como mediante un conjuro mágico, Alfaro pretende hacerlo del mismo modo mediante los calificativos de "posmoderno", "historicista" o incluso, "académico". Consecuente con su método, caricaturiza los complejos planteamientos de diversos autores bajo la simplicidad de la etiqueta: Foucault y Derrida "posmodernos", Gramsci "historicista”, Žižek "lacaniano". 
En este método crítico hay además una clara narrativa religiosa de salvación -iqué coincidencia: como en la ideología estalinista! (cfr. Blakely, 1969: 75-91)—, en la cual Lefebvre, después de pasar por el purgatorio, infierno y muerte a los que la interpretación de "García" lo sometió, resucita gracias a que Alfaro lo interpreta correctamente y lo supera. Este mecanismo de autobombo tras una descalificación rápida — sin prestarle atención a los textos que afirma criticar-, por supuesto, no se lo aplica solamente a "García" 20.

Prestándole atención a las críticas de Alfaro Vargas más allá de esta retórica autoritaria, aparecen numerosos vacíos conceptuales y argumentativos, desde los cuales, irónicamente, pretende encontrar falencias en otros autores. He indicado en páginas anteriores muchos de los que aparecen en su "contrarréplica", pues allí afirma criticar un libro y un artículo de mi autoría; no son, empero, casos aislados en su producción. Por razones como las que he planteado, de este intercambio fallido puedo concluir que las críticas de Alfaro Vargas a $L S M$ y a mi primera réplica, solo lo critican a él como crítico.

Hasta aquí mi intervención en esta polémica. Cuando una de las partes no discute siguiendo al menos las reglas básicas de la lógica y de la comprensión de lectura - para no hablar de temas de análisis y método-, la discusión carece de sentido. Decía Engels, a raíz de cierta recepción de El capital que "no tiene objeto alguno desvelarse de alguna manera por gente que no sabe o no quiere leer, que ya en ocasión de aparecer el primer tomo hizo

20 Por ejemplo, en "La sociología crítica de Henri Lefebvre" (2006: 101), ensaya un estado de la cuestión de estudios sobre Lefebvre. La revisión de los textos es en el mejor de los casos superficial cuando no negligente, como me he referido ya sobre sus valoraciones hacia mi libro, y solamente cumple la función de descalificarlos como "posmodernos", para que el autor se presente como alternativa crítica. Por ejemplo, descarta a Postmodern geographies de Soja -¿por su título?-, sin prestarle ninguna atención a la propuesta de ese autor de reformular un materialismo histórico y geográfico desde el concepto de espacio social (cfr. Soja, 1999), que en realidad constituye el tema central del libro. Por supuesto, es más fácil poner etiquetas que discutir tesis de fondo. mayores esfuerzos para entenderlo mal, que los que hubiesen sido necesarios para entenderlo correctamente" (en Marx, 2009, vol. 8: 1125).

Por mi parte, en adelante seguiré como sabio consejo esta observación de Engels.

\section{BIBLIOGRAFÍA}

Adorno, T.W. Dialéctica negativa. La jerga de la autenticidad. Madrid: Akal, 2005.

Aguirre Rojas, Carlos Antonio. Retratos para la historia. Ensayos de contrahistoria intelectual. La Habana: ICAIC, 2010.

Alfaro Vargas, Roy. "La sociología crítica de Henri Lefebvre". Revista de Ciencias Sociales 113-114 (III-IV). Universidad de Costa Rica, 2006: 97-104.

Alfaro Vargas, Roy. "Henri Lefebvre. Una contrarréplica a George I. García". Revista de Ciencias Sociales 125 (III). Universidad de Costa Rica, 2009: 103-115.

Alfaro Vargas, Roy y Cruz Rodríguez, Omar. "Teoría del conflicto social y posmodernidad". Revista de Ciencias Sociales 128-129 (II-III). Universidad de Costa Rica, 2009: 63-70.

Bajtín, Mijaíl. Estética de la creación verbal. Buenos Aires: Siglo XXI, 2005.

Bitsakis, Eftichios. Física contemporánea y materialismo dialéctico. México: Ediciones de Cultura Popular, 1975.

Blakely, Thomas J. La escolástica soviética. Madrid: Alianza, 1969.

Buchanan, Ian (ed.). Jameson on Jameson. Conversations on cultural Marxism. Durham: Duke, 2007.

Díaz, David; Boza, Alejandra e Ibarra, Eugenia (comps.). Tiempos de reflexión: la primera polémica historiográfica costarricense. San José: EUCR, 2007.

Engels, Friedrich. Anti-Dühring. México: Grijalbo, 1962.

Engels, Friedrich. Del socialismo utópico al socialismo científico. Madrid: R. Aguilera, 1976.

Gallardo, Helio. Abisa a los compañeros pronto. San José: Perro Azul, 2000.

Gallardo, Helio. Siglo XXI: producir un mundo. San José: Arlekín, 2006. 
García, George I. Las sombras de la modernidad. La crítica de Henri Lefebvre a la cotidianidad moderna. San José: Arlekín, 2001.

García, George I. La posmodernidad y sus modernidades. San José: EUCR, 2006.

García, George I. "Una réplica a La sociología crítica de Henri Lefebvre de Roy Alfaro Vargas". Revista de Ciencias Sociales 120 (II). Universidad de Costa Rica, 2008: 59-64.

Goldman, Lucian. El hombre y lo absoluto. El dios escondido. Barcelona: Península, 1985.

Grüner, Eduardo. "Foucault: una política de la interpretación”. Prólogo a Michel Foucault: Nietzsche, Freud, Marx. Buenos Aires: El Cielo por Asalto, 1995.

Hobsbawm, Eric. "Introducción a Karl Marx". Formaciones económicas precapitalistas. Buenos Aires: Pasado y Presente, 1974.

Hobsbawm, Eric. La era del imperio, 1875-1914. Barcelona: Crítica, 1998.

Jameson, Fredric. El giro cultural. Buenos Aires: Manantial, 1997.

Jameson, Fredric. Valences of the dialectic. Londres-Nueva York: Verso, 2009.

Jameson, Fredric. Una modernidad singular. Ensayo sobre la ontología del presente. Barcelona: Gedisa, 2004.

Jameson, Fredric. Documentos de cultura, documentos de barbarie. La narrativa como acto socialmente simbólico. Madrid: Visor, 1989.

Konstantinov et ál. Fundamentos de filosofía marxista-leninista. Materialismo dialéctico, parte 1. La Habana: Ed. de Ciencias Sociales, 1985.

Korsch, Karl. Marxismo y filosofía. México: Era, 1977.

Lefebvre, Henri. Lógica formal, lógica dialéctica. México: Siglo XXI, 1979.

Lefebvre, Henri. Critique of everyday life. Volume I: Introduction. Nueva YorkLondres: Verso, 1991.
Lefebvre, Henri. Espacio y política. El derecho a la ciudad 2. Barcelona: Península, 1976a.

Lefebvre, Henri. Tiempos equívocos. Barcelona: Kairós, 1976b.

Lefebvre, Henri. Critique de la vie quotidienne III. De la modernité au modernisme (pour une métaphilosopie du quotidien). París: L'Arche, 1981.

Lefebvre, Henri. Manifiesto diferencialista. México: Siglo XXI, 1970.

Lefebvre, Henri. The production of space. Oxford-Cambridge: Blackwell, 1997.

Lukács, György. Sociología de la literatura. Barcelona: Península, 1973.

Marx, Karl. Grundrisse. Londres: Penguin, 1993.

Marx, K. El capital. Crítica de la economía política. Buenos Aires: Siglo XXI, 2009.

Rojas Osorio, Carlos. La filosofía en el debate posmoderno. Heredia: EUNA, 2003.

Rose, Gillian. Hegel contra sociology. Nueva York-Londres: Verso, 2009.

Schmidt, Alfred. El concepto de naturaleza en Marx. México: Siglo XXI, 1976.

Soja, Edward. Postmodern geographies. The reassertion of space in critical social theory. Londres-Nueva York: Verso, 1999.

Thompson, Edward P. La formación de la clase obrera en Inglaterra. Barcelona: Crítica, 1989.

Williams, Raymond. Marxismo y literatura. Barcelona: Península, 1997.

Williams, Raymond. Keywords. Nueva York: Oxford University Press, 1983.

Williams, Raymond. La larga revolución. Buenos Aires: Nueva Visión, 2003.

Žižek, Slavoj. Porque no saben lo que hacen. Buenos Aires: Paidós, 1998.

Žižek, Slavoj. El espinoso sujeto. Buenos Aires: Paidós, 2001.

Fecha de ingreso: $30 / 05 / 2012$

Fecha de aprobación: 15/06/2012 